\title{
¿La salud de quién estamos defendiendo? Desigualdades sociales y sanitarias en tiempo de pandemia ${ }^{1}$
}

\author{
Marije Goikoetxea Iturregui \\ (coordinadora del grupo de trabajo Ética y Covid- $19^{2}$ y redactora de este texto) \\ Doctora en Derechos Humanos. Profesora de Ética. Universidad de Deusto. \\ Comité de Ética de Intervención Social de Bizkaia. Comité de Ética Asistencial \\ de Plena Inclusión de España \\ marije.goicoechea@deusto.es
}

\begin{abstract}
Lan hau COVID-19k eragindako gizarte- eta osasunkrisiari emandako erantzunei buruzko gogoeta kolektibo baten emaitza da, etika asistentzialarekin lotuta dauden gizarte- eta osasun-zerbitzuetako 22 profesionalek egina. Lanean, krisiak eragindako ondorioetako batzuk aztertzen dira: osasunzerbitzuetara sarbidea izateko orduan dauden desberdintasunak; pertsona-multzo jakin batzuek (gizarte- eta/edo osasun- hauskortasuneko egoeran adinekoak, desgaitasuna dutenak, bazterketaegoeran daudenak, babesgabetasun-arriskuan dauden adingabeak, indarkeriaren biktima diren emakumeak eta oso gizarte-egoera ahulean dauden beste batzuk) pairatu duten isolamenduaren ondoriozko kalteak; sufrimendu- eta marjinazioegoera berrien agerpena; eta isolamenduan hil direnek eta haien familiek bizitako egoera latza. Deliberazio etikoko esparruak ezartzea proposatzen da, eta, horien barruan, ekitate- eta inklusioirizpideetatik eta erkidego-harreman egokiak (Osasun Publikoaren Legea eta Osasunaren Mundu Erakundea) barne hartzen dituen osasun-kontzeptu batetik abiatuta, gizarte-politika bidezkoak eta eraginkorrak planteatzea herritar mota guztientzat.
\end{abstract}

\section{GAKO-HITZAK:}

Etika, Covid-19a, osasun-alorreko desberdintasunak, gizarte-bazterketa, gizarte-politikak, deliberazioa.
Este trabajo es el resultado de la reflexión de 22 profesionales de los servicios sociales y sanitarios, vinculados al ámbito de la ética asistencial, sobre las respuestas dadas a la crisis social y sanitaria provocada por la COVID-19. Se abordan algunas de sus consecuencias: desigualdades de acceso sanitarias; daños generados por el aislamiento impuesto a algunos grupos de personas (ancianas con fragilidad social y/o de salud, con discapacidad, en situación de exclusión, menores en riesgo de desprotección, mujeres víctimas de violencia y otras con gran vulnerabilidad); la emergencia de nuevas situaciones de sufrimiento y marginación; y la terrible situación vivida por quienes han fallecido en aislamiento y sus familias. Se plantea establecer ámbitos de deliberación ética en los que, partiendo de los criterios de equidad e inclusión y de un concepto de salud que incorpore las relaciones comunitarias satisfactorias (Ley de Salud pública y Organización Mundial de la Salud), plantee políticas sociales justas y eficaces para una ciudadanía diversa.

\section{Palabras Clave:}

Ética, Covid-19, desigualdades sanitarias, exclusión social, políticas sociales, deliberación.

\footnotetext{
${ }^{1}$ Una versión previa de este texto se publicó el 6-5-2020 en el blog de la Asociación de Bioética Fundamental y Clínica («http://www.asociacionbioetica.com/blog/la-salud-de-quien-estamos-defendiendo-desigualdades-sociales-y-sanitarias-en-tiempo-de-pandemia〉).

${ }^{2}$ Miembros del grupo de trabajo: Marije Goikoetxea, Juana Aza, Lourdes Zurbanobeaskoetxea, Concha Castells, Coro Rubio, Angel Bao, Porfirio Hernández, Celia Ramos, Txema Duque, Javier Yanguas, Boni Cantero, Pablo Ruiz, Rafael Armesto, Brígida Argote, Ángela Fernández, Mirian del Campo, María Ángeles Larrinaga, Zorione Benedicto, Carlos Romera, Yolanda Pérez, Marian García y Álvaro Mosquera.
} 


\section{Tiempo de deliberar para decidir}

Eudald Carbonel, codirector de los yacimientos de Atapuerca, piensa que la catástrofe humanitaria que estamos viviendo es uno de los pocos momentos de la historia en que se pone en peligro "la especie humana”. Un pequeño virus desconocido por nosotros ha puesto en jaque todo el omnipotente poder de la civilización, con sus conocimientos, sistemas, normas, pactos, técnicas y desarrollo. De pronto somos conscientes de nuestra fragilidad como humanidad y de nuestra interdependencia, no solo entre los pueblos y personas, sino del planeta y del cosmos en que habitamos. Nuestra pretendida y sobrevalorada autonomía moderna, tantas veces malentendida como autosuficiencia, parece que no es suficiente para el mantenimiento de lo más básico y perentorio: vivir.

Dice Reyes Mate ${ }^{3}$ que la vacuna será una tregua, pero no una solución definitiva a la fragilidad y dependencia de la humanidad, porque simplemente nuestra fragilidad no tiene solución, somos radicalmente interdependientes y vulnerables, y no solo biológicamente. Dependemos de las dependientas y reponedores de los supermercados, siempre, de las baserritaras y las personas que trabajan en el sector primario, siempre, de la compasión y el compromiso de quienes nos cuidan, siempre, de quienes limpian las calles y los espacios comunes, siempre, del aire que respiramos, SIEMPRE.

En esta cuarentena impuesta e involuntaria, en este tiempo de interrupción, podemos decidir. La palabra CRISIS significa etimológicamente "decisión"; Es el tiempo para DECIDIR qué debemos hacer, es el tiempo de la ÉTICA, de la RESPONSABILIDAD, de ver lo que está ocurriendo y reconocer cuáles son los VALORES imprescindibles a preservar ahora, en este tiempo extraordinario, y después, para avanzar como humanidad. Es el tiempo para escuchar, dialogar y DELIBERAR, para encontrar respuestas y soluciones PRUDENTES, como diría el profesor Gracia Guillén ${ }^{4}$; es el tiempo de acordar como comunidad humana, como sociedad, qué VALORES Y VIRTUDES debemos cuidar, proteger, desarrollar y crear. Es el tiempo de proponer lo que nos parece que es BUENO.

Este documento es el resultado de ese esfuerzo. Veintidós personas interesadas por la ética, principalmente profesionales de los servicios sociales y sanitarios, hemos intentado darnos cuenta y comprender lo que estaba ocurriendo. Ampliando la mirada, más allá de la necesidad de unidades de cuidados intensivos (UCl) y respiradores, hemos tratado de VISIBILIZAR por qué estaban sufriendo las personas, las familias, los barrios, las ciudades. flexion_o_2223677631.html.
Tras reconocer los hechos que generan incertidumbre y dolor, hemos indagado en sus porqués desde diferentes perspectivas e interpretaciones (económica, política, sanitaria, social, psicológica, educativa, et.), y nos hemos atrevido a proponer algunas orientaciones para algunos de los problemas que hemos descubierto. Problemas profundamente humanos como el miedo, el abandono, la injusticia, la soledad, la inseguridad, la desconfianza, la pobreza, el hambre, la exclusión, la discriminación, el dolor, el sinsentido, el mal morir y el mal vivir. También somos AGENTES MORALES en situaciones tan extraordinarias como la que estamos viendo y también ahora hemos de procurar lo éticamente correcto, las propuestas óptimas para respetar la dignidad y los derechos de todas las personas y colectivos.

Sin duda hemos partido de un gran capital humano: la confianza, entre nosotras y nosotros y en la sabiduría de tantas gentes expertas cada una en lo suyo, de diferentes edades, procedencias y estatus, ideologías políticas y religiosas, con miradas y experiencias diversas, que merecen ser escuchadas por ser valiosas y necesarias para encontrar propuestas buenas.

\section{2. ¿Una crisis sanitaria?}

Dicen que esta es una crisis sanitaria, que el problema mayor ha sido que el sistema sanitario no estaba preparado para una pandemia así. Los Gobiernos y hasta los/las gestores/as han adoptado mayoritariamente un lenguaje bélico: "es una guerra contra un virus que nos ha sorprendido y nos quiere matar". Hay que resistir ("Resistiré" ha sido el himno), confinarse $y$, de modo urgente, centrar todos los esfuerzos en poner a punto lo mejor que tenemos frente a la muerte, las UCI. Parecía que si hubiéramos estado preparados con más UCl y más respiradores, nada grave hubiera ocurrido.

Pero es mucho más; si comprendemos la salud como forma de vivir autónoma, solidaria y gozosa, según la define nuestra Ley de Salud Pública, es algo más que sobrevivir, es algo más que no enfermar; salud es tener capacidad de desarrollar un proyecto personal y social, de ser solidarias con las personas que nos rodean, de amarlas, de no abandonarlas. Es capacidad de cuidar, y de cuidarnos.

Algo se ha quebrado en la gestión de esta pandemia. La solidaridad de las personas jóvenes con las mayores, a la que tanto se ha aludido, ha quedado empañada por la interpretación de que su mayor bien es la mera supervivencia. Y pensamos que no, que nadie quiere la supervivencia a cualquier precio, al precio de la soledad, del miedo, de la falta del cariño de tus seres queridos, del abandono.

3 https://www.religiondigital.org/opinion/Reyes-Mate-tomarseserio-salud-deponer-progreso-cuarentena-iglesia-coronavirus-re-

4 GRACIA GUILLÉN, D. (2016): "Tomar decisiones morales. Del casuismo a la deliberación”, Dilemata, n을, 2016, pp. 15-31.
Siguiendo el empeño de algunas personas en utilizar la terminología militar, se están provocando graves daños "colaterales", porque lo urgente sirve como 
excusa para dejar de lado lo importante. Medidas excepcionales como las que estamos manteniendo, con graves consecuencias para las personas mayores, para las personas con discapacidad, para las personas en riesgo de exclusión, para la infancia, para las personas privadas de libertad... ¿hasta cuándo se pueden mantener? ¿La salud de quién estamos defendiendo? ¿No estaremos defendiendo la salud de una persona adulta de mediana edad, generalmente hombre, que tiene un trabajo y una vivienda confortable, con apoyo social, con colchón económico para el día después y para quien el confinamiento apenas supone una incomodidad?

Esta crisis saca a la luz la debilidad de los avances conseguidos en las políticas de coordinación entre las prestaciones sanitarias y de servicios sociales, en la asunción de la función, también cuidadora, del sistema de salud, en el modelo dominante biomédico y centrado en el hospital, que ha dejado de lado la atención comunitaria de la atención primaria y también los cuidados básicos, responsabilidad de los servicios sociales.

También nos muestra que es más fácil protocolizar para todos igual, con tratamientos uniformes que abordan de igual manera situaciones de partida distintas, con posiciones extremas y absolutas que solo protegen un valor: frenar los contagios. No es fácil compaginar medidas epidemiológicas con medidas humanitarias, pero no podemos dejar de lado cuestiones humanitarias por razones epidemiológicas. Protocolizar para todos igual es discriminatorio e injusto porque olvida la equidad y con ella los apoyos necesarios para que las personas en diversas situaciones y con déficits diversos puedan acceder al bien común de la asistencia sanitaria sea para curar, para aliviar o para obtener los cuidados necesarios para un buen morir.

Así, se indican aislamientos excesivos por el bien común como si fuera una indicación inocua, sin darnos cuenta de que en muchos casos no tiene nada inocuo y puede ser estimado como una auténtica mala praxis, por ejemplo en la atención al final de la vida o en algunas circunstancias de la asistencia a personas con enfermedad mental o con adicciones. Así, se ha olvidado la heterogeneidad del colectivo de personas mayores (siete millones en España), la dificultad para aislarse de los que no tienen dónde, la imposibilidad de hacerlo si la comida depende de la beca escolar de comedor, la necesidad de continuar atendiendo enfermedades y tratamientos crónicos que no pueden suspenderse, o los derechos de una persona con grave discapacidad a recibir apoyos para seguir un tratamiento intensivo que evite su discriminación. Como dice Javier Segura ${ }^{5}$ : "Urgentes medidas de brocha gorda que desatienden importantes detalles, estandarizan la complejidad y devuelven a los respectivos armarios los avances

${ }^{5}$ SEGURA DEL POZO, J. (2020): “Más allá del \#QuédateEnCasa y otras épicas”, Salud Pública y Otras Dudas, «https://saludpublicayotrasdudas.wordpress.com/author/javierseguradelpozo/>. conseguidos en la acción social y la formación de talento".

Y ¿por qué? Probablemente porque, de nuevo, en los comités de expertos y comisiones políticas donde se toman las decisiones, predominan las personas adultas de mediana edad, mayormente hombres, con una vivienda confortable y apoyo familiar y red social.

\section{El aislamiento total como respuesta única y homogeneizante para una sociedad diversa y con graves desigualdades}

Nuestra naturaleza social nos configura como seres interdependientes y es el reconocimiento reciproco lo que nos permite "sobre-vivir” más allá de lo puramente orgánico. La naturaleza humana es expresión de pertenencia a la especie pero también de desigualdad y diferencia.

El aislamiento por sí mismo es una situación potencialmente dañina para cualquier ser humano; el confinamiento impuesto y controlado está correctamente regulado y requiere supervisión judicial. La regulación de la pérdida de libertad, incluso en las personas en régimen penitenciario, no puede justificar la pérdida de otros derechos.

Entendemos y consideramos que ha sido correcta la medida de confinamiento de la población en esta situación. Pero reconocer y estar atentos a los daños que puede provocar forma parte de nuestra salud moral y de la obligación de los/as profesionales. Si bien en un primer momento esto no era posible, nos sorprende lo que se ha tardado (más de cuarenta días) en comenzar a prestar los apoyos necesarios para aquellas personas en que el aislamiento genera daños importantes. Sabemos cuáles son los factores principales que inciden en sus consecuencias: la voluntariedad o no de la situación; la capacidad de comprender la situación asumiendo que tendrá un final para poder tolerar la incertidumbre; el acompañamiento que otorga seguridad frente al miedo; la experiencia de confianza o de desconfianza; y contar con los recursos suficientes para cubrir las necesidades básicas.

La pandemia ha puesto en evidencia las desigualdades existentes anteriormente que NECESARIAMENTE diversifican la afectación de la enfermedad, y de las medidas propuestas, aunque se haya pretendido ofrecer una visión homogeneizadora de cómo afecta el contagio de la COVID-19. Se ha argumentado insistentemente que el bien común en situación de emergencia justifica la falta de atención al bien particular y la restricción de derechos individuales, dando por supuesto que lo común (vivir) es igual en toda la ciudadanía.

Pero el vivir no era el mismo vivir, y consecuentemente el confinamiento no ha sido el mismo vivir confinado en todas las personas: La 
imposibilidad de seguir manteniendo la economía sumergida y las actividades "laborales ilegales" o al menos "alegales", mayoritariamente feminizadas (mujeres migrantes sin regularizar, cuidadoras intensivas y sin derechos, de personas con graves dependencia, mujeres prostituidas, limpiadoras, etc.) han hecho emerger la precaria situación de pobreza extrema de muchas personas y familias que han acudido a los servicios sociales de base solicitando alimentos y cobijo. La escolarización en remoto ha mostrado la evidente brecha digital, y lo que es más importante, económica y social, de niñas y niños en situaciones de grave exclusión. La paradoja de la ocupación de los polideportivos, recurso necesario para el mantenimiento de la salud poblacional, por personas sin hogar o en situación de hacinamiento o de infravivienda, ha revelado los verdaderos datos y números tantas veces inciertos. La existencia de personas con deficiencias sensoriales incapaces de comprender y seguir las recomendaciones públicas para no enfermar, o deficiencias psíquicas que impiden comprender su razón de ser, ha mostrado que la convención de la ONU de los derechos de las personas con discapacidad no es solo para las situaciones sin riesgos, porque la discapacidad no desaparece de las personas en situación de alerta o de pandemia.

Parece necesario establecer con claridad criterios de flexibilización, de compensación o de apoyos en algunas personas que pueden vivir con gran sufrimiento, o que les puede generar daño, la situación de aislamiento prolongado. Las llamadas de teléfono como recurso generalizado utilizado en este tiempo puede ser un recurso escaso y hasta ineficiente si solo persigue un control de la situación de la persona y no generan un espacio para expresar su vivencia y sentirse escuchada, comprendida, validada en la misma.

Para evitar la homogenización que criticamos en esta aportación, vemos necesario perfilar algunas situaciones donde el aislamiento debe de ser establecido con cautela.

\section{- En el ámbito de los servicios sociales} residenciales, el aislamiento es especialmente penoso para muchas personas: genera graves consecuencias en centros con condicionantes físicos y espaciales muy limitados, con escaso apoyo personalizado o sin capacidad de percibirlo. Dicha situación se agrava, muchas veces, con condicionantes previos, que impiden a la persona adaptarse a la nueva situación (demencias, enfermedad mental, limitaciones psíquicas, adicciones, etc.) y si no se considera su especificidad pueden llegar a ser víctimas de maltrato por ello. Lo que nos permite soportar el confinamiento son, entre otras cosas, los recursos cognitivos, la capacidad de comprender los antecedentes y el desarrollo de los hechos $y$, sobre todo, de poder proyectar, imaginar $y$ prever consecuencias y escenarios futuros. Las personas con discapacidad intelectual y con deterioro cognitivo cuentan con menos recursos en este aspecto, $y$, cuanto mayor es su necesidad de apoyos (comunicativos y cognitivos), más precisan de referentes que las acompañen para mediar entre la realidad que es vivida como hostil y su vivencia. Del bienestar de las personas que viven en los centros ha dependido el modelo de confinamiento: el modelo estricto de confinamiento total en habitaciones para todas las personas, afectadas o no por el virus, sin contacto entre ellas, modelo que es muy seguro pero puede ser maleficente; o un modelo más laxo, con convivencia entre residentes y personal, con cautela, y estricto solo con los casos positivos de enfermedad, que aporta más seguridad emocional a las personas.

- El confinamiento en el hogar puede ser generador de daño si se prolonga mucho en el tiempo, tanto para las personas con capacidad limitada (por discapacidad intelectual o trastorno del espectro autista, por deterior cognitivo o por otras causas), como sobre la familia cuidadora, ya que la dependencia y la necesidad de apoyo intenso en el domicilio sin momentos de respiro (como los que proporciona la asistencia a un centro de día), sumadas al aislamiento, pueden ser altamente estresantes en la persona concernida, porque la deprivación social y de estímulos de todo tipo, en general, puede provocar retrocesos en su desarrollo y trastornos diversos.

- Las personas aisladas en sus domicilios con soledad prolongada no deseada, mayoritariamente ancianas, han sido durante el primer mes el colectivo que más ha sufrido la desproporción de esta medida de manera extrema, habiendo casos en que sus propias familias no las han acompañado, siguiendo las orientaciones emitidas por los medios de dejarles la comida o lo que necesiten en los felpudos, y marcharse. La relación telefónica con el entorno resulta un vínculo muy escaso en situaciones como la vivida, (de miedo, angustia e incertidumbre) y las videollamadas no están a su alcance, salvo en escasas ocasiones. Preocupa que no se valore adecuadamente esta realidad, existiendo incluso propuestas de que sean las últimas ciudadanas en poder salir del aislamiento, y especialmente que desde los servicios sociales no se les facilite el acceso a los apoyos para poder salir La falta de equipos de protección individual ha dificultado las visitas de personas del exterior que pudieran de manera limitada y supervisada apoyarles, como las/ los profesionales comunitarios y de centros de apoyo para visitas en domicilio. Los esfuerzos realizados por muchas profesionales y los recursos de videollamadas puestos a disposición en algunos territorios a través de ayudas públicas son merecedores de reconocimiento por haber supuesto un gran alivio para muchos casos.

- El aislamiento debe ser modulado y en ocasiones suspenderse periódicamente para evitar conflictos o conductas de alto riesgo, en algunas 
personas con enfermedad mental, trastornos del espectro autista, adicciones crónicas, discapacidad intelectual, o sin capacidad de comprensión del encierro, etc., tanto si viven en un medio residencial, con sus familias o son personas excluidas socialmente y albergadas en espacios comunitarios. Si bien cabe subrayar el gran esfuerzo de todos los cuerpos policiales para facilitar el abastecimiento, la higiene, el control social y los servicios esenciales de la población, no siempre se ha modulado adecuadamente y con la flexibilidad debida, el control poblacional para evitar contagios y la atención a las necesidad especiales de algunos colectivos, haciéndonos cargo de su vulnerabilidad y observando las diferencias.

- El aislamiento en los centros hospitalarios es probablemente el mayor problema para encontrar propuestas que compaginen la necesidad humana de ser acompañado/a por personas de confianza en situaciones de grave riesgo como la hospitalización en la enfermedad, y el riesgo de aumento de contagios tanto de los/as profesionales como de la población. Consideramos que la prudencia justifica el aislamiento total de las personas enfermas en los centros sanitarios suspendiéndose todas las visitas en un primer momento, pero del mismo modo que se han ido encontrando soluciones como la sectorización, la provisión de Equipos de Protección Personal (EPI) en otros mercados, la adecuación de locales y edificios como hospitales e incluso $\mathrm{UCl}$, no han existido apoyos, recursos y propuestas que minimicen el sufrimiento generado por el aislamiento en personas con enfermedades graves, personas con demencia, menores, personas con discapacidad etc. Suponemos que esta falta de abordaje es debida a la falta de personas con especialización en las necesidades emocionales y sociales, lo que nos lleva a pensar que las personas "expertas" han sido mayoritariamente del mismo perfil, es decir, capacitadas para establecer propuestas que minimicen el riesgo de contagio. Este curso tan extremo de acción ha supuesto en determinados hospitales y centros la falta de atención a otras patologías graves o muy graves, o al menos el retraso en sus tratamientos de modo desproporcionado e injustificado, con plantas y profesionales de varias especialidades sin posibilidad de atender a las personas enfermas que lo necesitaban.

- Las personas privadas de libertad, desde la instrucción adoptada el 12 de marzo por Instituciones Penitenciarias para continuar con las actuaciones de contención del virus en los establecimientos penitenciarios, han visto significativamente reducidas sus posibilidades de relación. Se han suspendido las visitas (comunicaciones íntimas, familiares y de convivencia), los permisos ordinarios, las salidas programadas, las actividades realizadas por entidades, la recepción de paquetes, etc.
Esta situación está generando importantes limitaciones en el día a día, que sufren especialmente las personas más empobrecidas, las que tienen menos habilidades, las que carecen de apoyos, quienes no tienen ingresos económicos, quienes sufren adicciones y/o enfermedad mental; a pesar del alivio de algunas medidas (incremento de llamadas semanales permitidas, como novedad algunas videollamadas). Además, para las personas sin apoyo familiar, la posibilidad de acogerse al tercer grado se han paralizado o dificultado.

- Resulta necesario resaltar que el confinamiento, en muchos casos, ha encerrado a las víctimas de violencia de género con sus maltratadores. Estas mujeres enfrentan dos pandemias: la COVID-19 y la violencia machista, viéndose obligadas a convivir las veinticuatro horas del día con su mayor enemigo, bajo el mismo techo. Se han puesto a disposición de estas mujeres teléfonos de atención y en algunos municipios se han establecido servicios de urgencia para dar respuesta a este terrible problema. Ahora más que nunca se hace necesario disponer de viviendas alternativas que hagan posible un confinamiento libre de violencia.

- Desde la declaración del Estado de Alarma, a los niños y niñas se les aplica un confinamiento total, sin entrar en las pocas excepciones que se han considerado para las personas adultas. Entendiendo la gravedad de la situación, valoramos que ha faltado una mirada que integrara las necesidades y especial vulnerabilidad de la infancia. Todas las expertas/ os coinciden en considerar que estas restricciones aplicadas a la infancia pueden afectar a su desarrollo - físico, social, educativo y emocionaly es necesario un apoyo y contención especial por parte de sus cuidadores, que seguramente no todas las familias están en condiciones de ofrecer. Se ha echado en falta la presencia de expertos/as en el área de la intervención social $y$, en particular, de infancia para poder haber asesorado y emitido recomendaciones para las vivencias de duelo y miedo que muchos niños y niñas están viviendo, así como como posibles espacios de "excepción” al confinamiento, con las medidas y limitaciones que se establecieran.

La declaración del Estado de Alarma ha supuesto el cierre de centros educativos especiales, centros de día, etc. Para muchos niños y niñas con discapacidad o necesidades especiales, también para sus familias, esto ha supuesto la pérdida de un espacio social y una atención directa a sus problemas, con graves consecuencias para su desarrollo. Después de seis semanas, se comienza tímidamente a vislumbrar la posibilidad de recuperar estos recursos y los seguimientos y tratamientos individuales que siguen los niños y niñas con estas necesidades especiales: psicoterapias, rehabilitación, Atención Temprana, etc. En estos casos, al ser tratamientos especializados y basados en la relación, resulta 
muy difícil "sustituirlos” por una intervención a distancia.

- La generalidad de las medidas de confinamiento ha respondido de forma uniforme a una situación de crisis y de emergencia, sin tener presente que muchas familias vulnerables que viven con alta precariedad en situación de hacinamiento, en viviendas con falta de espacio, luz, ventilación, etc. Tampoco que la educación a distancia está limitada en muchos casos por la brecha digital lo que genera situaciones de injusticia y producen inequidad al tratar por igual situaciones muy diferentes.

Consideramos de interés y necesidad especial la infancia que está en situación de riesgo de violencia intrafamiliar, de origen machista o de tipo filio-parental o con medida de protección tras separación del medio familiar. Hay un número significativo de niños y niñas que se encuentran en situación de riesgo con programas municipales y forales de intervención socioeducativa familiar. Esta intervención, básica para garantizar su protección y mantenimiento en el medio familiar, se ha suspendido o limitado en una situación de sobreexposición al estrés de ese medio familiar, que ya sufre limitaciones y conflictos importantes. Una vez más, la disposición profesional para el seguimiento telefónico parece claramente insuficiente.

Se deben considerar también los casos que se están produciendo durante este periodo en los que se debe asumir una medida de guarda o tutela, que supone la separación temporal del medio familiar, y aquellos otros en que existe una medida de protección y están acogidos/as en otra familia o en centros residenciales. En estos casos, el confinamiento, en ocasiones unido a una cuarentena de aislamiento en una habitación, supone una situación especialmente preocupante por la pérdida de relación con sus progenitores/as.

\section{La justicia como criterio en las políticas sanitarias y de servicios sociales}

El reconocimiento de la IGUAL DIGNIDAD es la que fundamenta la igualdad de derechos de la ciudadanía, también en esta situación de alarma que estamos viviendo. Desde siempre, y también ahora, han existido modos de tratamiento y relación que quebrantan la dignidad. Se dan en las siguientes situaciones ${ }^{6}$ :

- Cuando se trata a la persona como puro medio que vale para algo. Decimos entonces que la persona no tiene valor en sí, sino precio, y se tolera el maltrato y la lesión de sus derechos para conseguir determinados intereses personales, económicos, lucrativos, etc. El caso claro sería

${ }^{6}$ ETXEBERRIA, X. (2005): Aproximación ética a la discapacidad, Bilbao, Universidad de Deusto. la explotación de una persona para los propios intereses.

- Cuando la persona es considerada un no valor, por carencia de capacidades o recursos, y, en consecuencia, sufre menosprecio, indiferencia o, incluso, exclusión o marginación (no es tenida en cuenta, se la aparta si nos estorba o molesta, se la aísla o margina para no ser vista, etc.). Esta situación no dependerá solamente de las condiciones de déficit o capacidad de la persona, sino sobre todo de la situación subjetiva de quien observa y se relaciona (mayor o menor control emocional) y, especialmente, del compromiso ético y el vínculo personal que existan entre ambas personas.

- Por último, se atenta contra la dignidad cuando se considera a la persona como un disvalor peligroso, porque supone una carga para otros/as o para el sistema, por sus conductas inadecuadas, por generar gasto, molestia o insatisfacción en su comunidad de referencia. En estos casos, puede plantearse su eliminación y discriminación (modelo eugenésico) con respecto a los recursos sociales o sanitarios, por considerar que son «desproporcionados» o "poco eficientes" para la calidad de vida que se obtendrá.

En términos generales, con respecto a las políticas de salud pública, el ámbito residencial se queda a medio camino entre el hospital y la comunidad, en "tierra de nadie", con la excepción del control de las cocinas y de la intervención cuando surge un brote de transmisión alimentaria o de otro tipo. La orientación preventiva en sus instalaciones, en la práctica del cuidado, en la formación de su personal, queda a su propia responsabilidad, sin la orientación, por ejemplo, de un servicio de medicina preventiva de la que sí dispone un hospital. Y no es que haya que "medicalizar" las residencias, pero hay que reconocer que son instituciones cerradas donde residen muchas personas de riesgo, y su abordaje no es en absoluto comparable a la de cualquier domicilio. Este hecho unido a la todavía no suficientemente desarrollada coordinación sociosanitaria, ha podido generar discriminación para estos colectivos de personas que no viven en domicilios propios, especialmente en una situación de recursos escasos, como ha podido ser el de los equipos de protección personal. Habrá que repensar en el futuro el modelo de prevención de la salud en el ámbito residencial.

Consideramos, escuchando algunas noticias, comentarios, artículos y argumentaciones de expertos/as, que hay tres grupos sociales que están en riesgo importante de vivir una de las tres situaciones de discriminación expuestas: no ser destinatarias de prestaciones por ser un mero medio que ahora no se requiere para lograr el fin (por ejemplo, se mantiene el salario del profesional y por tanto no es ya necesario para el profesional seguir prestando atención), no ser un valor (por ejemplo, hay vidas humanas a las que se da menos 
valor que a otras ), o ser un disvalor que hay que eliminar o controlar (por ejemplo, porque su atención en igualdad de condiciones que el resto genera peligro de contagio). Consideramos que el riesgo ha aumentado en las personas ancianas, las personas con discapacidad importante (física y/o psíquica), las personas en situación de exclusión social (puede que antes algunas de ellas fueran explotadas y fueran consideradas útiles) y, especialmente, en el caso de las mujeres pertenecientes a estos grupos.

Son varias las personas o colectivos ${ }^{7}$ que han alertado del aumento de la APOROFOBIA (discriminación por ser pobre), GERONTOFOBIA (discriminación por edad) Y DEFICIENTISMO (discriminación por discapacidad) y queremos hacernos eco de ello. En concreto, queremos visibilizar las siguientes situaciones:

- La exclusión social es un proceso en cuya esencia están el aislamiento, la falta de vínculos y de apoyo social. El decreto del Estado de Alarma y la obligación de confinamiento en el domicilio ha hecho que muchas personas con grave exclusión y sin hogar hayan tenido que recurrir, en ocasiones de manera involuntaria, a las plazas de acogida de emergencia que las administraciones han dispuesto de manera apresurada en dispositivos variados (polideportivos, albergues juveniles, residencias, etc.). Por otro lado, las personas que se encontraban alojadas en centros de acogida, permanente o "invernales", se han visto sujetas al confinamiento prolongando y forzoso en las condiciones (y también las dificultades) de convivencia durante las veinticuatro horas.

Las circunstancias y problemáticas previas al confinamiento que presenta cada persona condicionan de forma decisiva el acceso y la permanencia en los recursos sociales. En este sentido, para las personas con algún trastorno mental (diagnosticado o no), así como para las personas con adicciones, el confinamiento supone una dificultad añadida ya que limita gravemente las posibilidades de relajamiento mental ("andar a mi rollo"). Por otro lado, el uso o abuso de sustancias legales e ilegales produce en muchas personas alteraciones en el comportamiento que afectan gravemente a la convivencia, ya de por sí difícil en un confinamiento forzoso y prolongado.

Las personas en situación de exclusión social siempre han sido "temidas" y estigmatizadas a partes iguales: son un "otro" del que nos queremos diferenciar y al que no nos preocupamos mucho por conocer... y lo desconocido genera miedo. Además, muchas de ellas tienen un aspecto característico: físicamente deterioradas, desaliñadas, con falta de higiene, etc., y son acusadas de no aportar nada a la sociedad.

${ }^{7}$ Adela Cortina, Plena Inclusión, Sociedad Española de Geriatría y Gerontología, etc.
En un momento de crisis y miedo (a la enfermedad, a la escasez de recursos tras la pandemia, etc.), se da el caldo de cultivo necesario para que la estigmatización de las personas en exclusión aumente, y se refuerce en el imaginario colectivo su imagen de propagador de enfermedades (por su aspecto y delicada salud), acaparador de recursos (por su baja empleabilidad), delincuente, etc.

El estado de salud de las personas en situación de exclusión social es más precario que el de la media de la población, convirtiéndolas en población de mayor riesgo, lo que debiera de entenderse como una razón para que la atención sanitaria fuese mayor, pero sin embargo no se han planteado desde el sistema sanitario una atención "de apoyo" a los lugares habilitados. Todo el dispositivo de acogida de emergencia ha puesto de manifiesto, más claramente si cabe, los déficits existentes, no solamente en aspectos cuantitativos ( $\mathrm{n}-$ de personas en exclusión residencial grave) sino sobre todo en los cualitativos, ya que ahora podemos observar casi en una única mirada las personas que están atendidas y las que no lo están por parte de los distintos sistemas del bienestar, llamando especialmente la atención las dificultades de acceso al Sistema Sanitario (Atención Primaria por no disponer de TIS y a la Red de Salud Mental) y al Sistema de Servicios Sociales (de Atención Primaria y Secundaria), y de permanencia en ellos.

- Un grupo “desconocido” hasta ahora ha sido el de las personas, mayoritariamente mujeres, y familias migradas o con empleos precarios, que en esta situación han perdido los recursos escasos que obtenían normalmente a través de trabajos irregulares como cuidados, limpieza, empleo sumergido, etc. Este grupo está emergiendo poco a poco como solicitantes de ayudas en los servicios sociales de base por falta principalmente de alimentos y productos de higiene. Todavía hoy, hay quienes no se reconocen como sujetos con derecho a una prestación social por ser personas que nunca se habían imaginado estar en una situación de pobreza o riesgo de exclusión.

- La gestión de la epidemia de COVID-19 ha tenido una demoledora mirada de las personas mayores que debe de ser repensada, al menos por dos motivos: ha focalizado en la edad el riesgo de enfermar y morir, en lugar de en variables de salud; y ha "culpabilizado" a los centros residenciales de personas mayores en la extensión y deriva de la pandemia. Hay una identificación permanente en los medios de comunicación entre ser mayor y mortalidad por la infección por COVID-19. Si bien solo el $20 \%$ de las personas mayores son personas fragilizadas de modo importante, lo que las convierte en un grupo para el que no está indicado un tratamiento intensivo, han sido frecuentes los argumentos de edad para limitar determinados recursos 
sanitarios específicos, como las UCl, y organizar la distribución de los centros sanitarios y sociales en caso de contagio. Las personas mayores han sido así potencialmente discriminadas, trasmitiendo a la sociedad la idea de personas menos valiosas, invitándolas a protagonizar un "altruismo obligatorio" sin posibilidad de participación y de dudosa reciprocidad. Han sido discriminadas, por tanto, también en su autonomía, no dejándoles participar en la toma de decisiones en las cuestiones que les afectan y asumiendo sobre ellas, al mismo tiempo, una actitud paternalista de sobreprotección de las que difícilmente han podido escapar.

La edad nunca debe de ser un criterio excluyente para la atención, como tampoco residir en un centro de alojamiento permanente con otras personas mayores. El sistema sanitario debe procurar similares prestaciones con similares criterios científicos que para el resto de la población, tanto para tratamientos de agudos como de crónicos, como puede ser el abordaje del dolor, de la salud mental, de las dificultades para la autonomía personal o para las relaciones sociales. Las intervenciones de profesionales ajenos a los servicios sociales y sanitarios (militares, ONG, etc.) en la atención a las residencias de personas mayores, y no en otros colectivos, evidencia la falta de consideración en los planes de atención y cobertura sociosanitaria.

- El confinamiento ha sido durante siglos el modo habitual en que en nuestras sociedades se ha abordado las necesidades de las personas con discapacidad, especialmente con discapacidad intelectual. El llamado modelo prescindente (prescindir socialmente de estas personas) ha derivado en diversos momentos de la historia en un modelo claramente eugenésico, que está siendo sustituido por un enfoque social de la discapacidad recogido en la Convención de sus Derechos de la ONU del año 2006, ratificada por España en el 2008.

El llamado "modelo social" nos descubre que todas las personas podemos ser discapacitadas si nos encontramos con barreras que impidan el desarrollo de nuestras capacidades y la participación social en condiciones de igualdad. Poner esto de manifiesto es esencial porque solo la excepcionalidad de la situación justifica esta mirada focalizada en las personas con discapacidad y/o en situación de dependencia, lo que nada tiene que ver con la escisión artificial entre nosotras, las personas normales, y ellas, las personas con discapacidad, generando una alteridad extraña y ajena.

El colectivo de personas con discapacidad, especialmente con discapacidad intelectual o en situación de dependencia, ha sido definido desde el comienzo de la pandemia como grupo de especial vulnerabilidad para la COVID-19. Pero este reconocimiento no ha ido acompañado de otros efectos: a día de hoy se desconoce la incidencia de la infección en este colectivo, cómo se están cubriendo las diferentes necesidades en los confinamientos, las hospitalizaciones, los criterios de acceso a recursos específicos como $\mathrm{UCl}$, etc. Las personas con alguna discapacidad se han diluido en el grupo de personas mayores y su invisibilidad (como tantas veces) se ha manifestado, entre otras cosas, en la falta de recomendaciones y apoyos a las propias personas con discapacidad, a sus familiares (que en general son sus personas de apoyo), a entidades de cuidado y defensa de sus derechos, residencias, etc., $y$, de forma más dolorosa, en momentos de discriminación en el acceso a servicios sanitarios y apoyos específicos necesarios en cada caso. La ausencia de información y casuística en los medios de comunicación y de debate público promovido desde las organizaciones y asociaciones que representan a estas personas, genera riesgos añadidos de exclusión e injusticia, así como de trato inadecuado.

La situación vivida en la pandemia por parte de las personas más vulnerables sanitaria y socialmente pone de manifiesto una crisis muy importante de cuidados y responsabilidad y una evidente ruptura del llamado "pacto intergeneracional de cuidados" que puede generar riesgos graves de daños y maltrato.

El desarrollo en las últimas décadas de los servicios de atención a personas vulnerables y en situación de exclusión, por parte del Estado, como expresión de justica, puede haber debilitado la conciencia de ligazón y ob-ligazón de las personas dentro de los contextos de apoyos naturales: familias, vecindario, amigos/as, etc. La pandemia está poniendo en escena los límites y contradicciones del propio sistema. Un problema muy importante que puede generar, si no se aborda convenientemente, un debilitamiento de la cohesión social y abandono y discriminación de las personas más vulnerables.

Como contrapunto muy importante reconocemos la irrupción de personas voluntarias que de manera libre y solidaria se han ofrecido gratuita y altruistamente a ayudar en lo que fuese necesario. Es indudable su gran aportación y su valor tanto para las personas que han cuidado o atendido como para la sociedad en general. Es destacable sin embargo la falta de liderazgo para sistematizar y dar cauce a su aportación, que ha quedado en muchos casos sin ser aprovechada para mejorar y aliviar la situación.

El "nada humano me es ajeno" (dicho de Terencio atribuido a Séneca) no parece una opción ahora, sino una elección en clave de consecuencias, porque apela a la responsabilidad, más allá de los derechos. Se actualiza el hacerse cargo porque el nosotros, lo común, se construye en el reconocimiento y respeto a la dignidad del otro, que me completa en $\mathrm{mi}$ humanidad (Ricoeur, Lévinas). 


\section{Morir y hacer duelo en tiempos de la COVID}

En estos meses de pandemia han muerto muchas personas como consecuencia del contagio del virus SARS-CoV-2 (a 27 de abril, 1.269 personas fallecidas con enfermedad confirmada en Euskadi, y 23.822 en España), bien porque ya partían de procesos delicados de salud que no les han permitido hacer frente a la enfermedad, o bien porque esta les ha afectado de manera cruenta y la evolución ha sido desfavorable. La falta de respuesta a los tratamientos intensivos, y en algunos casos el hecho de no ser candidatas a ellos, requeriría, como marca nuestra legislación, una atención propia para bien morir que claramente ha sido deficitaria en muchos de los casos.

La centralización de la asistencia sanitaria en los tratamientos agudos e intensivos, la atención telefónica de atención primaria en los domicilios, la prohibición de visitas y acompañamiento familiar a las personas enfermas en hospitales y centros residenciales, y la falta de cualificación y de recursos necesarios en determinados lugares para unos correctos cuidados paliativos, han sido las causas principales de este mal morir. El fallecimiento de una persona es algo único que no se puede posponer para cuando la crisis pase, ni se puede recuperar, y que aunque parezca que no deja consecuencias negativas, puede dejar graves huellas emocionales en las personas allegadas, y dificultar el duelo posterior.

En los centros residenciales de servicios sociales, la tendencia ha sido la no derivación de las personas consideradas como paliativas a otros medios. Este hecho, que en condiciones normales se considera como buena práctica en los centros que disponen de capacitación interna o con apoyos externos sanitarios, sin embargo, no ha resultado adecuado en muchas situaciones. Los centros residenciales no tienen por qué contar con recursos sanitarios especializados, pues no son centros sanitarios, sino lugares donde vivir en los que se prestan los apoyos para las actividades de la vida cotidiana. Por tanto, lo correcto es que las personas residentes accedan como ciudadanas, en igualdad de condiciones que el resto, a las prestaciones sanitarias comunitarias (atención primaria, unidades de cuidados paliativos, hospitalización a domicilio u otros). Se ha visto que, en numerosas situaciones, estas prestaciones han sido inaccesibles por la gestión establecida por los/ las responsables sanitarios/as, o por la ausencia de una coordinación sociosanitaria eficiente.

Si bien en pocos días se flexibilizó la medida de restricción absoluta de visitas para las personas en procesos finales de vida, han existido diversos criterios a la hora de determinar cuáles son las personas que se encuentran en el momento final de su vida, y más concretamente en situación terminal. Se ha identificado este momento especialmente con la agonía, cuando la persona ya está muy desconectada y la comunicación es difícil, lo que ha dificultado en los días previos las despedidas, la expresión de los afectos y la resolución de asuntos pendientes, acciones tan necesarias para un buen morir.

Las restricciones por riesgo de contagio también posterior al fallecimiento han dificultado, y en algunos casos han impedido, poder ver $y$ reconocer a la persona fallecida y despedirse de ella, siendo especialmente duro si el fallecimiento ha sido imprevisto. La dificultad continúa con la organización de los ritos funerarios y la despedida social de la persona fallecida... Para que haya un buen proceso de duelo, sin sentimientos de culpa y experiencia de abandono familiar, es importante, entre otras cosas, que se haya podido hacer bien tanto el acompañamiento como la despedida. Se comprenden las limitaciones en esta situación por los riesgos para la salud pública, pero no podemos olvidar los derechos de las personas al final de la vida, recogidos en nuestro marco legislativo, y que deben de garantizarse en la medida de lo posible. La situación de alerta actual no anula el derecho de la persona a recibir información veraz sobre su proceso y enfermedad, a rechazar un tratamiento, a unas correctas decisiones de representación en caso de incapacidad y al alivio del sufrimiento mediante una asistencia paliativa de calidad, derechos poco respetados en muchos casos.

Es necesario y urgente facilitar el acompañamiento de las personas en el final de sus días, permitiendo la presencia, como mínimo, de una persona familiar o allegada durante un tiempo suficiente, en un espacio íntimo, siempre respetando las normas de higiene y de prevención, y proporcionándole el equipo adecuado si está en un centro sanitario o residencial. En ese sentido, cabe reconocer y destacar la iniciativa de los centros residenciales, y de algunas unidades hospitalarias, que, además de lo anterior, han facilitado las despedidas de otras personas, amistades y familiares mediante otros sistemas de comunicación (teléfonos, lecturas de correos electrónicos, videollamadas, etc.).

\section{Las obligaciones éticas de los y las profesionales y la responsabilidad ciudadana}

Los colectivos profesionales, asistenciales y de servicios, han demostrado gran integridad y compromiso en esta crisis, como lo ha reconocido la ciudadanía general en los aplausos de las ocho de la tarde de cada día. La responsabilidad profesional emerge en las personas que han cultivado determinados valores y modo de concebir su profesión. Quienes no han cultivado dichos valores y virtudes no es fácil que estén dispuestas a arriesgarse. Por eso han existido casos de personas que no han cumplido con lealtad aquello a lo que se habían comprometido previamente con 
la sociedad. Entendemos que un/a profesional es alguien dotado/a de capacidades técnicas y éticas suficientes como para comprometerse con las personas de una comunidad y aportarles un bien, un beneficio. El fundamento por tanto está en dicho compromiso (promete hacer el bien) que, como decimos, se ha dado en un gran número de personas, pero no en otras.

De todos los colectivos, el gran protagonista de la crisis generada por la COVID-19 ha sido el de los profesionales sanitarios/as, especialmente los de ámbito hospitalario, por varios motivos. El más visible ha sido la grave afectación de la salud de gran parte de la población, que ha colapsado las urgencias $\mathrm{y}$ ha necesitado de ingresos $\mathrm{y}$ de medidas intensivas. $\mathrm{Y}$, en segundo lugar, por la dificultad de contar con medios materiales y humanos para hacer frente a la pandemia, lo que ha expuesto a profesionales a jornadas intensivas y al contagio.

Sin embargo, ha habido otros escenarios que no son secundarios, sino paralelos e igual de importantes. La crisis ha revelado quiénes son realmente profesionales esenciales que generan un bien social: personal de supermercados, transportistas, limpiadoras, cuidadoras y auxiliares geriátricas, celadores/as, educadores/as, trabajadoras/ es sociales, psicólogos/as maestra/os, policías, integradores/as sociales.., etc., y tantas otras personas que quizá no han recibido ni la protección ni el reconocimiento a su compromiso leal y en ocasiones heroico. Sin ellas la población se habría podido ver expuesta sin remedio al hambre, la afectación de la salud, la precariedad y a la desprotección en general frente a la epidemia.

Se hace imprescindible también una reflexión colectiva de todos los aspectos afectados en esta crisis, reconociendo que, junto a la salud biológica, están en juego otros factores de salud como son los psicosociales. La consecuencia más inmediata, que ya se ha hecho notar, es el aumento de la brecha social, que agrava la vulnerabilidad de las personas que ya eran vulnerables, y deja en situación de fragilidad a otras muchas. Y la brecha de género, por ser las mujeres las más afectadas en esta crisis, por su mayoritario papel de cuidadoras en los ámbitos público y privado. De ahí la importancia de que además del reconocimiento legal de ser esenciales que ya tienen los servicios sociales y sus profesionales, se les dé la visibilidad política y social que les corresponde, por ser cuidadores del contexto social que soporta el confinamiento para la salud y las consecuencias socioeconómicas que ya se están derivando de él.

Han existido conflictos de carácter ético (y en ocasiones también legal) entre la responsabilidad de atención a la población, y la seguridad y el cuidado de su salud. No está bien abusar del carácter vocacional y solidario, y permitir que las personas trabajen en condiciones límites y/o de desprotección o sobreexponerlas a la fatiga y al burnout. Tampoco es correcto en virtud de la propia seguridad, negarse a atender necesidades que no pueden ser prestadas a través del teletrabajo. Como siempre, los extremos no suelen ser la mejor opción en situaciones de conflictos de valor. Creemos que ha faltado la deliberación para poner en marcha cursos de acción que distribuyeran los equipos de protección en función del riesgo y no del estatus o la categoría profesional y facilitaran el acompañamiento personal y emocional de los/las profesionales, también en los momentos en los que se requiera movilidad o cambios en la actividad laboral para atender necesidades urgentes.

La situación tan intensa que viven los equipos profesionales y las personas afectadas gravemente por la crisis, por las circunstancias y condiciones en las que enferman y fallecen las personas, así como las solicitudes imprevistas de movilidad y cambios en la actividad laboral para cubrir necesidades importantes y urgentes, las coloca en un grave riesgo emocional que no ha sido suficientemente valorado a la hora de establecer medidas de protección y apoyo emocional. La responsabilidad no es solo de las personas profesionales, es también de las entidades e instituciones que tienen el deber de buscar y distribuir de manera eficiente los medios existentes (humanos y materiales) para que la población y las profesionales que más riesgos físicos y emocionales sufren en esta situación sean protegidas prioritariamente.

No es menos importante, hablando de responsabilidad y de solidaridad, la excelente respuesta de la mayoría de la población quedándose en casa, con lo que ello supone no solo de aislamiento y pérdida de relaciones sino también, en muchísimos casos, de pérdida del propio sustento. Creemos que las autoridades en su conjunto no han reconocido dicha responsabilidad y han comenzado a extralimitarse en las medidas de control impuestas con un fundamento marcadamente paternalista. Queremos subrayar la necesidad que tenemos las personas de cumplir con nuestras propias obligaciones morales, independientemente de nuestra condición social y de salud. Es comprensible que dichas obligaciones se vean limitadas si su cumplimiento puede suponer un riesgo contrastado y demostrado para terceras personas. Si no es así, se podrá aconsejar y recomendar a la población determinadas medidas y orientaciones para el cuidado de la salud, pero no se pueden imponer coactivamente, más en el caso de que supongan una limitación de sus derechos.

\section{7. ¿Y ahora qué? Mirando al futuro}

En el momento de publicar este artículo se inicia la fase de la llamada "nueva normalidad", es decir, de ir retomando poco a poco la normalidad, con prudencia, para seguir vigilando la extensión del virus, pero reconociendo y confiando en la responsabilidad ciudadana en la gestión de su 
salud, sin discriminación por edad y respetando la autonomía personal, que no es otra cosa que la capacidad de cumplir con las propias obligaciones morales.

Hemos aprendido mucho en estas semanas, muchas cosas buenas, pero también cosas que pueden mejorar y es nuestra obligación intentarlo seriamente si de ello depende que las personas, todas, podamos vivir decentemente. Compartimos a continuación lo más importante de lo aprendido en nuestro grupo:

- Que no todas las personas somos iguales, que algunas son más vulnerables y que requieren que se atiendan sus necesidades de una manera distinta; que no valen fórmulas sencillas para realidades complejas. Que si tratamos a todas las personas igual, faltaremos a la equidad y al reconocimiento de que la igual dignidad merece igual estima y consideración, pero no hacer lo mismo.

- Que hay personas que tienen serias dificultades para ser reconocidas como sujetos de derechos, también de derechos a la asistencia sanitaria, a la libertad de decidir, a la vivienda, a la educación... y que entre ellas la mayoría son mujeres.

- Que la salud es más que biología mecanicista individual que funciona correctamente, que es vida autoinsuficiente con significado, que necesita relación y compromiso.

- Que las ayudas de emergencia, beneficentes y graciables, no pueden ni deben de ser, en una sociedad justa, el modo habitual de enfrentar el empobrecimiento de las personas, por lo que se debe de garantizar una renta básica a toda la ciudadanía que asegure unos mínimos de vida saludable (al menos con los estándares básicos que existen cuando una persona está hospitalizada por enfermedad).

- Que hay servicios esenciales que no se pueden sustituir por teletrabajo, pues exigen intervenciones cualificadas de cuidado que pueden generar graves riesgos si se suspenden, por lo que deben de retomarse lo antes posible los servicios de día para personas con dependencia y/o discapacidad, los tratamientos individualizados de tipo sociosanitario que necesitan adultos/as y menores con discapacidad o necesidades especiales, y las medidas educativas de carácter comunitario para familias en situación de riesgo y personas con vulnerabilidad social.
- Que en cualquier momento podemos morir y que no es lo mismo morir bien que mal, aislado/a o acompañado/a, porque morir siempre es conmorir, como vivir siempre es con-vivir. Por eso debemos reconocer como sociedad la deuda que hemos contraído de las personas que han fallecido en absoluta soledad y la ausencia de despedida de sus familiares, y debemos de hacer todo lo necesario para aliviar con recursos psicológicos suficientes el daño que han sufrido sus allegados.

- Que la "crisis de los cuidados" y el "envejecimiento de nuestras sociedades", temas estrella en nuestros foros académicos, políticos y económicos, han sido en este tiempo retos que nos han devuelto la conciencia de que las relaciones comunitarias en los entornos naturales son imprescindibles.

- Que poner en marcha un sistema eficaz y suficientemente dimensionado de servicios sociales, que pueda preservar y enriquecer las relaciones y los apoyos comunitarios, es imprescindible, si no queremos que el próximo gran colapso sea el de los servicios sociales de base facilitando ayudas de emergencia para necesidades básicas a una gran parte de la población.

- Que hay compromisos y lealtades, profesionales o voluntarias, que no se pagan con "salarios", sino con "honorarios", es decir con reconocimiento social a quien más allá de sus obligaciones legales, presta una atención excelente corriendo riesgos, porque sabe que en la relación asistencial no solo se juega la dignidad de la persona atendida, (cuidada, educada, protegida, lavada, alimentada o acariciada) sino el propio proyecto de autorrealización personal.

- Que el lucro y la distribución desigual de los bienes básicos escasos, (como por ejemplo la prioridad de los deportistas en el acceso a los test diagnósticos frente a los grupos de riesgo, o a los profesionales de la intervención social y sanitaria), es inmoral e injusto.

- Que la justicia requiere trasparencia, argumentación, conocimientos y deliberación entre diferentes perspectivas, desde la convicción de que cualquier mirada es siempre limitada y necesita complementarse desde otras experiencias, siempre afectadas y subjetivas, porque la subjetividad está en la mirada y no en el virus. 


\section{Miembros del grupo de trabajo}

Marije Goikoetxea, psicóloga, profesora de Ética, Universidad de Deusto, CEIS Bizkaia, CEA Plena Inclusión (coordinadora y redactora).

Juana Aza, enfermera especialista en geriatría, Instituto Foral de Asistencia Social-Diputación Foral de Bizkaia, CEIS Bizkaia.

Lourdes Zurbanobeaskoetxea, médica, Servicio de Valoración y Orientación, Diputación Foral de Bizkaia, coordinadora sociosanitaria, CEIS Bizkaia.

Concha Castells, epidemióloga, Departamento de Salud, Gobierno Vasco, Asociación DMD-DHE.

Coro Rubio, psicóloga, ASPACE-Bizkaia. CEIS Bizkaia.

Angel Bao, psicólogo, Atención Temprana-Diputación Foral de Bizkaia, CEIS Bizkaia.

Porfirio Hernández, psiquiatra, Federación Vasca de Deporte Adaptado, CEIS Bizkaia.

Celia Ramos, trabajadora social, Ayto. de Bilbao, CEIS Bizkaia.

Txema Duque, trabajador social, Ayto. de Bilbao.

Javier Yanguas, psicólogo, Fundación Aubixa.

Boni Cantero, trabajadora social, Ayto. de VitoriaGasteiz, CEIS Araba.
Pablo Ruiz, coordinador técnico, Asociación Bizitegi

Rafael Armesto, abogado, FEVAS-Plena Inclusión, CEIS Bizkaia.

Brígida Argote, enfermera especialista en geriatría, IFBS-Diputación Foral de Áraba, CEIS Áraba.

Ángela Fernández, trabajadora social, Ayto de Ermua, CEIS Bizkaia.

Mirian del Campo, psicóloga, Fundación Gizakia, CEIS Bizkaia.

María Ángeles Larrinaga, trabajadora social, Red de Salud Mental de Bizkaia, CEIS Bizkaia.

Zorione Benedicto, trabajadora social, CEIS Gipuzkoa.

Carlos Romera, jurista, mediador y educador social, Asociación Goiztiri, CEIS Bizkaia.

Yolanda Pérez, técnica del Departamento de Salud, Gobierno Vasco, CEIS Bizkaia.

Marian García, trabajadora social, CEIS Bizkaia.

Álvaro Mosquera, educador social, Residencia Aspaldiko, profesor, Universidad de Deusto. 